\title{
Comparison of minimally invasive surgery with standard open surgery for vertebral thoracic metastases causing acute myelopathy in patients with short- or mid-term life expectancy: surgical technique and early clinical results
}

\author{
Massimo Miscusi, MD, PhD, ${ }^{1}$ Filippo Maria Polli, MD, PhD, ${ }^{2}$ Stefano Forcato, MD, ${ }^{2}$ \\ Luca Ricciardi, MD, ${ }^{1}$ Alessandro Frati, MD, PhD, ${ }^{2,3}$ Marco Cimatti, MD, PhD, ${ }^{2}$ \\ Luca De Martino, MD, PhD, ${ }^{2}$ Alessandro Ramieri, MD, ${ }^{4}$ and Antonino Raco, MD ${ }^{2}$
}

'Department of Medico-Surgical Sciences and Biotechnologies, and 'NESMOS Department, Sapienza University of Rome, Latina and Rome; ${ }^{3}$ Department of Neurosurgery, IRCCS Neuromed., Pozzilli; and ${ }^{4}$ Don Gnocchi Foundation, Milan, Italy

\begin{abstract}
OBJECT Spinal metastasis is common in patients with cancer. About $70 \%$ of symptomatic lesions are found in the thoracic region of the spine, and cord compression presents as the initial symptom in $5 \%-10 \%$ of patients. Minimally invasive spine surgery (MISS) has recently been advocated as a useful approach for spinal metastases, with the aim of decreasing the morbidity associated with more traditional open spine surgery; furthermore, the recovery time is reduced after MISS, such that postoperative chemotherapy and radiotherapy can begin sooner.

METHODS Two series of oncological patients, who presented with acute myelopathy due to vertebral thoracic metastases, were compared in this study. Patients with complete paraplegia for more than 24 hours and with a modified Bauer score greater than 2 were excluded from the study. The first group $(n=23)$ comprised patients who were prospectively enrolled from May 2010 to September 2013, and who were treated with minimally invasive laminotomy/laminectomy and percutaneous stabilization. The second group $(n=19)$ comprised patients from whom data were retrospectively collected before May 2010, and who had been treated with laminectomy and stabilization with traditional open surgery. Patient groups were similar regarding general characteristics and neurological impairment. Results were analyzed in terms of neurological recovery (American Spinal Injury Association grade), complications, pain relief (visual analog scale), and quality of life (European Organisation for Research and Treatment of Cancer [EORTC] QLQ-C30 and EORTC QLQBM22 scales) at the 30-day follow-up. Operation time, postoperative duration of bed rest, duration of hospitalization, intraoperative blood loss, and the need and length of postoperative opioid administration were also evaluated.
\end{abstract}

RESULTS There were no significant differences between the 2 groups in terms of neurological recovery and complications. Nevertheless, the MISS group showed a clear and significant improvement in terms of blood loss, operation time, and bed rest length, which is associated with a more rapid functional recovery and discharge from the hospital. Postoperative pain and the need for opioid administration were also significantly less pronounced in the MISS group. Results from the EORTC QLQ-C30 and QLQ-BM22 scales showed a more pronounced improvement in quality of life at followup in the MISS group.

CONCLUSIONS In the authors' opinion, MISS techniques should be considered the first choice for the treatment for patients with spinal metastasis and myelopathy. MISS is as safe and effective for spinal cord decompression and spine fixation as traditional surgery, and it also reduces the impact of surgery in critical patients. However, further studies are needed to confirm these findings.

http://thejns.org/doi/abs/10.3171/2014.10.SPINE131201

KEY WORDS minimally invasive spine surgery; thoracic metastases; myelopathy; quality of life; oncology; technique

ABBREVIATIONS ASIA = American Spinal Injury Association; EORTC $=$ European Organisation for Research and Treatment of Cancer; KPS $=$ Karnofsky Performance Scale; MISS = minimally invasive spine surgery; NSAID = nonsteroidal antiinflammatory drug; $\mathrm{QOL}$ = quality of life; RBC = red blood cell; VAS = visual analog scale. SUBMITTED January 4, 2014. ACCEPTED October 9, 2014.

INCLUDE WHEN CITING Published online February 27, 2015; DOI: 10.3171/2014.10.SPINE131201.

DISCLOSURE The authors report no conflict of interest concerning the materials or methods used in this study or the findings specified in this paper. 
$\mathrm{T}$ HE spine is the third most common site for cancer cells to metastasize, following the lungs and the liver. Approximately $60 \%-70 \%$ of patients with systemic cancer will have spinal metastasis. Of these symptomatic lesions, approximately $70 \%$ are found in the thoracic region of the spine, particularly at the level of T4-7. Of the remaining lesions, $20 \%$ are found in the lumbar region, and $10 \%$ are found in the cervical spine. More than $50 \%$ of patients with spinal metastasis have several levels of involvement. ${ }^{31,39}$

Approximately $90 \%$ of cancer patients with spinal metastases have bone and/or back pain, followed by radicular pain. Half of these patients have sensory and motor dysfunction, and more than half have bowel and bladder dysfunction. Five percent to $10 \%$ of cancer patients present with cord compression as their initial symptom; among these patients, $50 \%$ are nonambulatory at diagnosis, and $15 \%$ are paraplegic..$^{10}$

Radical vertebrectomy with curative purposes is rarely indicated. In fact, total en bloc spondylectomy is reserved for the curative resection of vertebral tumors in patients for whom it is the most suitable and least damaging option, as in the case of a single intracompartmental lesion. ${ }^{19,23,27}$

Surgery may be palliative, rather than curative, for patients with short- or mid-term life expectancy, aimed to preserve or, whenever possible, improve their quality of life (QOL). In such cases, surgery is considered useful for the stabilization of involved segments, for spinal cord or root decompression, and for tissue diagnosis. The initial functional score is the most important prognostic factor for the neurological recovery of patients undergoing surgery. The ability to ambulate at the time of presentation is a favorable prognostic sign. Loss of sphincter control is a poor prognostic feature, and is mostly irreversible.

Minimally invasive spine surgery (MISS) has been extensively used for successful pain relief through vertebroplasty and kyphoplasty techniques in patients with vertebral metastases. Only recently, more complex MISS procedures, including endoscopy-assisted spinal cord decompression, tumor resection and spinal reconstruction through mini-open approaches, and percutaneous placement of pedicle screws, have been advocated as useful approaches for spinal metastases. , $, 610,16,22,24,29,30$ The goals with MISS are to achieve outcomes equivalent or superior to those of traditional open spine surgery and to reduce the impact of surgery in critical patients with poor general and neurological conditions with short- or mid-term life expectancy.

Although the superiority of MISS over open spinal surgery has not yet been demonstrated, a trend toward MISS is occurring. This trend is likely due to the lower complication rates and approach-related morbidity associated with MISS, with minimal soft-tissue trauma, reduced intraoperative blood loss/risk of transfusion, improved cosmesis, decreased postoperative pain and narcotic usage, and shorter hospital stays with faster return to work and, thus, reduced overall health care costs. ${ }^{2,12,13,16-18,24,26,33,38}$ Furthermore, the use of MISS in oncological patients allows for a more rapid initiation of postoperative chemotherapy and radiotherapy than would be permitted by traditional approaches alone.
Despite the benefits described above, some reports have suggested that the minimal surgical exposure used in MISS techniques is insufficient for the complete treatment of the pathology due to significantly decreased visualization, ability to debulk the lesion, and to decompress the spinal cord. ${ }^{3,26}$ The aim of this study was 2-fold: to investigate the safety and efficacy of these MISS techniques in the removal of tumors that have invaded the spinal canal, compressed the spinal cord, and produced acute neurological impairment, and to investigate their safety and efficacy in segmental spine fixation.

\section{Methods}

A series of 23 oncological patients (6 men and 17 women, mean age 58 years) were prospectively enrolled in this study between May 2010 and September 2013. These patients presented with myelopathy caused by single or multiple spinal cord segment compression due to vertebral metastatic lesions. Patients with a complete neurological deficit (American Spinal Injury Association [ASIA] Grade A) for more than 24 hours and a modified Bauer score greater than 2 were excluded from the study. ${ }^{20}$ All patients underwent minimally invasive laminotomy/laminectomy and percutaneous stabilization. This series was compared with another series of 19 patients (7 men and 12 women with a mean age of 52 years), whose records were retrospectively collected before May 2010, who had similar clinical and neurological characteristics, and who underwent posterior spinal cord decompression and stabilization through traditional open surgery.

Both groups received the same surgical treatment, that is, posterior spinal cord decompression and spinal fixation. According to inclusion criteria, regardless of histology, no patient would have benefitted from different and more aggressive surgical goals, such as pedicle removal or total vertebrectomy.

Open surgery was performed via the median posterior approach and extended 1 level above and 1 level below the involved segments, and included a bilateral laminoarthrectomy and a spinal fixation through pedicle screws connected to rods. The MISS procedure was first based on the placement of purely percutaneous pedicle screws; using 2 radiography arches (one giving the anteroposterior view and the other the lateral view), a 4-handed surgery was performed. A further step required a mini-open median posterior approach to expose the laminae of the involved segments. A simple laminotomy, with preservation of the spinous process, except when it was invaded by tumor, was performed, to avoid the exposure and removal of the posterior joints, and to minimize muscle detachment and retraction (which causes excessive bleeding).

For both of the techniques, fragments of the tumors were sampled for histopathological analysis; a nonsuction drain was left in place for 24 hours at the end of the procedure. Evaluation of general and neurological conditions was performed at admittance and at the 30-day follow-up after surgery (Karnofsky [KPS] and ASIA scores). At the same follow-up, we evaluated the surgical results (operative time, blood loss, surgical complications, and duration of hospitalization), neurological recovery, pain relief (eval- 
uated using the visual analog scale [VAS] score and the type and amount of analgesic therapy), and QOL (evaluated by the European Organization for Research and Treatment of Cancer QOL questionnaire [EORTC QLQ-C30] and the more specific Bone Metastases module [EORTC QLQ-BM22]) and compared the results between the 2 groups. ${ }^{1,7-9}$

The statistical analyses were performed using SPSS software (version 15, SPSS, Inc.). A p value of $<0.01$ was considered significant.

\section{Illustrative Cases \\ Case 1}

A 75-year-old man with a 2-year history of white cell renal carcinoma, which was treated with chemotherapy and radiotherapy, presented with sudden leg weakness, hyperreflexia, and urge incontinence (ASIA Grade C, KPS Score 60, modified Bauer Score 2), after a 1-month history of severe thoracic spinal pain (VAS Score 90 of 100), which was unresponsive to common analgesic agents. Imaging results showed a lesion that was invading the T-12 body and its right pedicle, with initial invasion of the spinal canal (Fig. 1A-C). The patient then underwent a pure percutaneous short fixation with transpedicular screws at T-11, L-1, and at the left pedicle of T-12, followed by a mini-open approach, centered at the level of T-12, with a laminotomy.

The patient was mobilized on the 1st postoperative day, with an almost complete resolution of thoracic pain (VAS Score 20 of 100). Intraoperative blood loss was 200 $\mathrm{ml}$, and a red blood cell (RBC) transfusion was not necessary. No opioids were administered during the postoperative period, and the patient was discharged from the hospital on the 4th postoperative day. A postoperative CT scan showed complete decompression of the spinal cord, with segmental fixation (Fig. 1D-F). At the follow-up, the patient exhibited complete restoration of his neurological deficit (ASIA Grade E), and analgesic therapy with nonsteroidal antiinflammatory drugs (NSAIDs) was only given as needed.

\section{Case 2}

A 77-year-old woman had a 7-year history of follicular thyroid cancer and previous lung and spine metastases that were treated with left inferior pulmonary lobectomy and right partial T-10 corpectomy with T9-11 anterolateral fixation, respectively. She came to our attention with a new onset of severe thoracolumbar pain (VAS Score 90 of 100) with leg weakness (ASIA Grade C). The progressionfree interval of disease was 3 years, after the conclusion of adjuvant chemotherapy and radiotherapy. Imaging showed diffuse spinal metastatic localizations with pathological fractures at T-9, T-10 and T-11; severe kyphosis of the dorsal spine was evident. MRI also showed spinal cord compression at the T10-11 levels, due to extradural metastatic tissue and progressive kyphosis (ASIA Grade C, KPS Score 60, modified Bauer Score 2) (Fig. 2A and B).
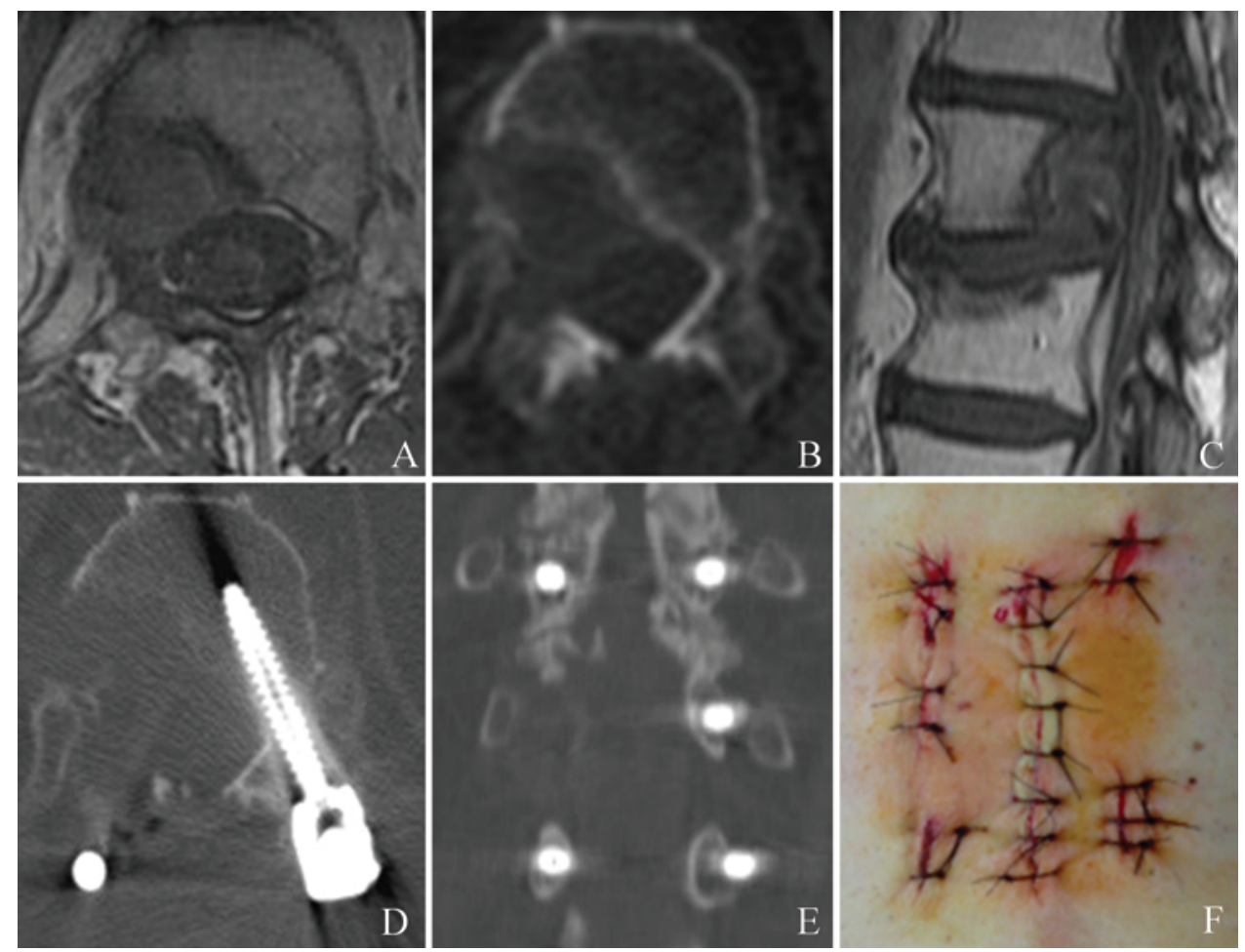

FIG. 1. Case 1. Images obtained in a patient who underwent MISS. A-C: Axial (A and B) and sagittal (C) T1-weighted gadoliniumenhanced MR images of the thoracic spine, showing a metastatic lesion invading the T-12 body and its right pedicle, with initial invasion of the spinal canal. D and E: Postoperative CT scans demonstrating complete decompression of the spinal cord with segmental fixation; note the unilateral pedicle fixation at the level of the lesion. F: Photograph showing the final aesthetic result of the surgery. Figure is available in color online only. 

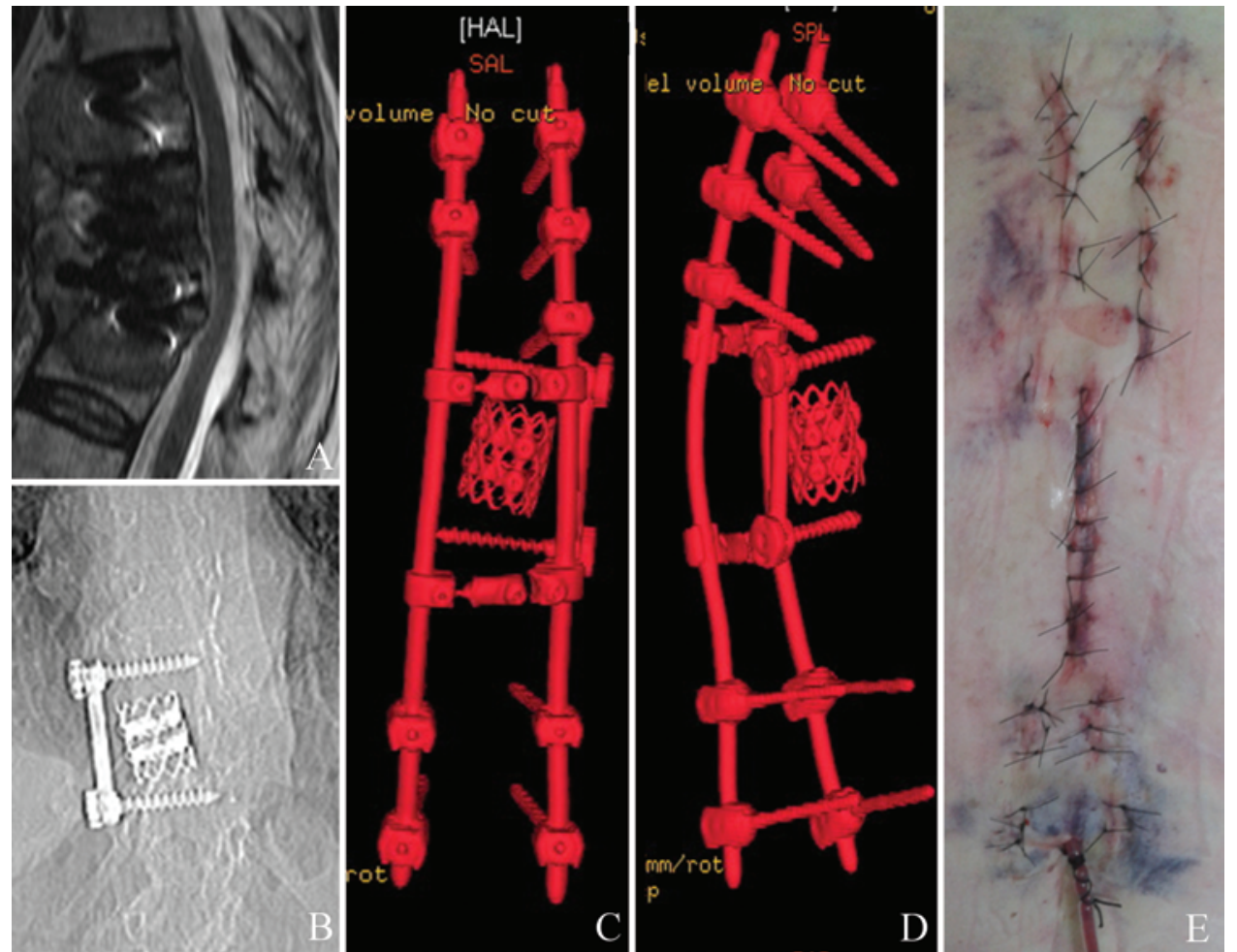

FIG. 2. Case 2. Images obtained in a patient who underwent MISS. A and B: Sagittal T2-weighted MR image (A) and lateral radiograph $(B)$ showing diffuse spinal metastatic localizations with pathological fractures of T-9, T-10, and T-11 in a patient who had undergone previous surgery for partial vertebral body substitution of T-10 and anterior T9-11 fixation; a severe kyphosis of the dorsal spine is evident. C and D: Three-dimensionally reconstructed postoperative CT scan demonstrating the final fixation construct from T-7 to T-11, with unilateral pedicle fixation at T-9. E: Photograph showing the final aesthetic result of the surgery. Figure is available in color online only.

The patient underwent a pure percutaneous fixation with placement of transpedicular screws at T-7, T-8, T-9 (only on the left pedicle), L-1, and L-2, followed by a mini-open approach centered at the level of T10-11, with laminotomy and positioning of 2 cross-links. The patient was mobilized on the 1st postoperative day. Intraoperative blood loss was $350 \mathrm{ml}$, and an RBC transfusion was not necessary. No opioids were administered during the postoperative period, and the patient was discharged on the 8th postoperative day. A postoperative CT scan showed complete decompression of the spinal cord and the final fixation construct (Fig. 2C and D). At follow-up, the patient's neurological condition had improved (ASIA Grade D), opioids were stopped, and analgesic therapy with NSAIDs was started.

\section{Results}

For the combined groups $(\mathrm{n}=42,29$ women and 13 men, mean age 56 years), the primary tumors were lung cancer $(\mathrm{n}=15,35.7 \%)$, breast cancer $(\mathrm{n}=12,28.6 \%)$, myeloma $(n=4,9.5 \%)$, clear cell renal carcinoma $(n=3,7 \%)$, melanoma $(\mathrm{n}=3,7 \%)$, prostate cancer $(\mathrm{n}=3,7 \%)$, ovarian cancer $(\mathrm{n}=1,2.4 \%)$, and thyroid cancer $(\mathrm{n}=1,2.4 \%)$ (Table 1). A single level was involved in 29 patients $(69 \%)$, while 2 or more segments were involved in 13 patients (31\%). In 18 patients (42.8\%), the fracture involved a single column (open surgery: 52.6\%, MISS: $34.8 \%$ ), while 2 or
3 columns were the site of metastases in the other cases $(57.2 \%)$ (Table 1$)$.

The 2 groups were similar in terms of general and neurological conditions. All patients preoperatively presented with an overall mean KPS score of 58 (57.89 and 58.26 in the open surgery and MISS groups, respectively; $p=0.94)$; the mean overall modified Bauer score was 2.35 (2.6 and 2.1 in the open surgery and MISS groups, respectively; $\mathrm{p}$ $=0.135$ ) (Table 1). Pre- and postoperative ASIA scores for both groups are given in Table 2. The preoperative neurological assessment showed a prevalence of ASIA Grade D in both groups. Regarding neurological status, 27 patients (64\%) showed an improvement, 12 patients $(28 \%)$ remained stable, and only 3 patients (7\%) worsened (1 in the open surgery group and 2 in the MISS group; these results were not due to surgery-related complications, but to bad general condition). No statistically significant differences in terms of neurological improvement were demonstrated between the 2 groups $(p=0.574)$.

Surgical and hospitalization data are given in Table 3. There were no perioperative complications, except in 1 patient in the MISS group who developed a urinary tract infection. One patient in the open surgery group died on the 14th postoperative day due to metastatic hepatic failure. The mean operation length was 3.2 hours in the open surgery group, while it was 2.2 hours in the MISS group $(\mathrm{p}<0.01)$.

The mean intraoperative blood loss was $900 \mathrm{ml}$ in the 
TABLE 1. Demographic and clinical data*

\begin{tabular}{|c|c|c|c|c|}
\hline Variable & $\begin{array}{c}\text { Open } \\
\text { Surgery }\end{array}$ & MISS & Total & $\mathrm{p}$ Value \\
\hline \multicolumn{5}{|l|}{ Demographic data } \\
\hline No. of patients & 19 & 23 & 42 & \\
\hline Sex ratio $(M / F)$ & $7: 12$ & $6: 17$ & $13: 29$ & \\
\hline Mean age in yrs & 51.74 & 58.48 & 55.42 & \\
\hline \multicolumn{5}{|l|}{ Clinical data } \\
\hline KPS score & 57.89 & 58.26 & 58.09 & 0.94 \\
\hline Modified Bauer score & 2.6 & 2.1 & 2.35 & 0.135 \\
\hline \multicolumn{5}{|l|}{ Spinal metastases } \\
\hline 1 level & $14(73.6)$ & $15(65.2)$ & $29(69)$ & \\
\hline$\geq 2$ levels & $5(26.3)$ & $8(34.8)$ & $13(31)$ & \\
\hline 1 column & $10(52.6)$ & $8(34.8)$ & $18(42.8)$ & \\
\hline$\geq 2$ columns & $9(47.4)$ & $15(65.2)$ & $24(57.2)$ & \\
\hline \multicolumn{5}{|l|}{ Primary cancer } \\
\hline Lung & $8(42)$ & $7(30.4)$ & $15(36)$ & \\
\hline Breast & $6(31.6)$ & $6(26)$ & $12(28.6)$ & \\
\hline Myeloma & 0 & $4(17.4)$ & $4(9.5)$ & \\
\hline Kidney & $2(10.5)$ & $1(4.4)$ & $3(7)$ & \\
\hline Melanoma & 0 & $3(15.8)$ & $3(7)$ & \\
\hline Prostate & $2(10.5)$ & 0 & $3(7)$ & \\
\hline Ovary & $1(5.3)$ & 0 & $1(2.4)$ & \\
\hline Thyroid & 0 & $1(4.4)$ & $1(2.4)$ & \\
\hline
\end{tabular}

* Values are number of patients (\%) unless stated otherwise.

open surgery group and $240 \mathrm{ml}$ in the MISS group (p < 0.01 ). Twelve patients in the open surgery group required postoperative $\mathrm{RBC}$ transfusions, while none of the patients in the MISS group required additional blood supply. In the open surgery group, the mean postoperative duration of bed rest was 4 days with a mean length of hospitalization of 9.25 days, and in the MISS group the mean duration of postoperative bed rest was 2 days with a mean length of hospitalization of 7.2 days $(\mathrm{p}<0.01)$.

Preoperative scoring for QOL was similar in both groups, according to the EORTC QLQ-C30 and EORTC QLQ-BM22 scales (Table 2). Results from the EORTC QLQ-C30 questionnaire showed a mean overall improvement at follow-up of 11.7 in QOL score (open surgery: 9.8 and MISS: 13.6; $\mathrm{p}=0.009), 13.8$ in the functional scale score (open surgery: 13.5 and MISS: 14.1, $\mathrm{p}=0.03$ ), and 17.5 for the symptoms scale score (open surgery: 17.2 and MISS 17.8, $\mathrm{p}=0.006$ ). The QLQ-BM22 scale showed a mean overall improvement at follow-up of 10.3 in the functional scale score (open surgery: 4.65 and MISS: 14.07, p $=0.025$ ), and 10.54 in symptom scale score (open surgery: 8.45 and MISS: $11.4, \mathrm{p}=0.007)$. The preoperative VAS scores did not significantly differ between the groups $(\mathrm{p}>$ 0.01; Table 4). At follow-up, 27 patients (64\%) showed an improvement in VAS score (open surgery: $53 \%$ and MISS: $74 \%$ ), while 12 patients (28\%) were stable (open surgery: $37 \%$ and MISS: $22 \%$ ), and 3 patients (7\%) worsened (open surgery: $10 \%$ and MISS: $4 \%)(\mathrm{p}=0.007)$.

In the preoperative period, 5 patients received analgesic drugs as needed, and 25 patients received them at follow-
TABLE 2. ASIA, EORTC QLQ-C30, and QLQ-BM22 scores*

\begin{tabular}{|c|c|c|c|c|}
\hline Variable & Open Surgery & MISS & Total & $\mathrm{p}$ Value \\
\hline \multicolumn{5}{|l|}{ ASIA } \\
\hline \multicolumn{5}{|l|}{ Preop } \\
\hline A & 3 & 2 & 5 & \\
\hline$B$ & 2 & 3 & 5 & \\
\hline C & 6 & 7 & 13 & \\
\hline$D$ & 8 & 11 & 19 & \\
\hline$E$ & 0 & 0 & 0 & \\
\hline Postop & & & & 0.574 \\
\hline Improved & $12(63)$ & $15(65)$ & $27(64)$ & \\
\hline Stable & $6(31)$ & $6(26)$ & $12(28)$ & \\
\hline Worse & $1(5)$ & $2(8)$ & $3(7)$ & \\
\hline \multicolumn{5}{|l|}{ Mean EORTC score } \\
\hline \multicolumn{5}{|l|}{ QLQ-C30 } \\
\hline QOL† & & & & 0.009 \\
\hline Preop & 16 & 17.2 & 16.6 & \\
\hline Postop & 25.8 & 30.8 & 28.3 & \\
\hline Functional scales $†$ & & & & 0.03 \\
\hline Preop & 59.1 & 55.9 & 57.5 & \\
\hline Postop & 72.6 & 70 & 71.3 & \\
\hline Symptom scales $\ddagger$ & & & & 0.006 \\
\hline Preop & 33 & 32.6 & 32.8 & \\
\hline Postop & 15.8 & 14.8 & 15.3 & \\
\hline \multicolumn{5}{|l|}{ QLQ-BM22 } \\
\hline Functional scales $†$ & & & & 0.025 \\
\hline Preop & 75.15 & 70.86 & 72.58 & \\
\hline Postop & 79.8 & 54.93 & 82.88 & \\
\hline Symptom scales $\ddagger$ & & & & 0.007 \\
\hline Preop & 16.65 & 17.5 & 17.16 & \\
\hline Postop & 8.2 & 6.1 & 6.62 & \\
\hline
\end{tabular}

* Values are number of patients (\%) unless stated otherwise.

† For QOL and functional scales, scores range from 0 to 100 , and highest scores represent better quality of life;

‡ For symptom scales, scores range from 0 to 100 and highest scores represent worst symptoms.

up (open surgery: 10, MISS: 15). Twenty-one patients preoperatively received NSAIDs, and 9 patients received NSAIDs at follow-up (open surgery: 4 and MISS: 5). Sixteen patients patients were given morphine preoperatively, and 8 patients were given morphine at follow-up (open surgery: 5 and MISS: $3, \mathrm{p}=0.01$ ).

\section{Discussion}

Spinal metastasis with spinal cord involvement is a frequent complication in cancer patients, occurring in $30 \%-50 \%$, and the thoracic spine is often the site of these metastatic lesions. ${ }^{11,27,37}$ These metastatic lesions can significantly impact a patient's QOL as a result of disabling pain, fractures, or even paralysis due to spinal cord compression. ${ }^{15,28}$ The incidence of spinal metastases is likely to increase as cancer patients live longer, which is partly due to early detection, as well as to improvements in medical care. ${ }^{4}$ With recent advances in cancer treatment and 
TABLE 3. Results of surgery

\begin{tabular}{lccc}
\hline \multicolumn{1}{c}{ Variable } & Open Surgery & MISS & p Value \\
\hline Surgery data & & & \\
\hline Op time in hrs & 3.2 & 2.2 & \\
\hline Mean & $2.5-4.5$ & $1.5-3$ & \\
\hline Range & & & $<0.01$ \\
\hline Blood loss in ml & 900 & 240 & \\
\hline Mean & $350-1500$ & $180-400$ & \\
\hline Range & & & \\
\hline Hospitalization & 12 & 0 & $<0.01$ \\
\hline No. of RBC transfusions & 0 & 1 & \\
\hline No. of complications & & & $<0.01$ \\
\hline Postop bed rest in days & 4 & 2 & \\
\hline Mean & $2-10$ & $1-3$ & \\
\hline Range & & & $<0.01$ \\
\hline Time to discharge in days & 9.25 & 7.2 & \\
\hline Mean & $5-14$ & $4-9$ & \\
\hline Range & 1 & 0 & \\
\hline No. of deaths & &
\end{tabular}

care, patients have longer overall survival, thus elevating the risk for systemic metastases, but also emphasizing the importance of treating these lesions to prevent undesired sequelae, and to preserve or, whenever possible, improve the quality of their remaining life..$^{35,36}$

Surgery in the majority of cases of spinal metastases does not have a curative aim, but it provides mechanical stabilization, pain relief, and maintenance of neurological function. ${ }^{4}$ Goals of surgery are decompression of neural structures, confirmation of the primary diagnosis, pain relief, debulking or removing the tumor mass to allow for a more effective adjuvant therapy, and spinal stabilization to prevent deformity and allow mobilization.

Surgery in spinal metastases is indicated for cases of progressive neurological deficit before, during, or after chemotherapy and radiotherapy, intractable pain unresponsive to conservative treatment, need for histological diagnosis, radioresistant tumor histology (e.g., renal cell carcinoma and melanoma), and spinal instability (e.g., vertebral fracture).

Many aggressive surgical strategies have been developed to improve outcomes for patients with metastatic spine disease. These strategies are associated with high morbidity and complication rates, especially in patients with numerous neoplasm-associated comorbidities; the indication for aggressive surgery is limited in patients in poor general condition and with a limited life expectancy, such as in our series. ${ }^{10,23}$ In fact, patients with spine metastases often present in poor general condition, suffering from comorbidities, malnourishment, diminished immunity, considerable pain, and limited overall survival. In these cases, extensive surgical procedures or prolonged hospital stays are neither acceptable nor feasible in many patients. Therefore, surgical risks must be weighed against life expectancy and QOL to justify standard surgical interventions.
TABLE 4. VAS scores and analgesic therapy

\begin{tabular}{|c|c|c|c|c|}
\hline Variable & Open Surgery & MISS & Total & $p$ Value \\
\hline \multicolumn{5}{|l|}{ VAS score } \\
\hline \multicolumn{5}{|l|}{ Preop } \\
\hline $0-20$ & 2 & 3 & 5 & \\
\hline 40 & 4 & 3 & 7 & \\
\hline 60 & 6 & 8 & 14 & \\
\hline 80 & 3 & 5 & 8 & \\
\hline 100 & 4 & 4 & 8 & \\
\hline Postop & & & & 0.007 \\
\hline Improved & $10(53)$ & $17(74)$ & $27(64)$ & \\
\hline Stable & $7(37)$ & $5(22)$ & $12(28)$ & \\
\hline Worse & $2(10)$ & $1(4)$ & $3(7)$ & \\
\hline \multicolumn{5}{|c|}{ Analgesic therapy* } \\
\hline \multicolumn{5}{|l|}{ Preop } \\
\hline As needed & 2 & 3 & 5 & \\
\hline NSAID & 10 & 11 & 21 & \\
\hline Morphine & 7 & 9 & 16 & \\
\hline \multicolumn{5}{|l|}{ Postop } \\
\hline As needed & 10 & 15 & 25 & \\
\hline NSAID & 4 & 5 & 9 & \\
\hline Morphine & 5 & 3 & 8 & \\
\hline$p$ value & 0.015 & 0.01 & & \\
\hline
\end{tabular}

Recent advances in percutaneous instrument placement have led to the development of minimally invasive approaches for the treatment of spinal metastases that result in less postoperative pain, shorter overall hospital stays, less intraoperative blood loss, and an earlier start to adjuvant therapy. ${ }^{14,21,22,25,32}$ The advantages of these techniques include smaller incisions, which limit wound complications, and the avoidance of back muscle detachment and retraction, which causes postoperative pain and profuse bleeding, thus reducing intraoperative blood loss that requires additional blood supply. These advantages are crucial for maintaining and improving the QOL of cancer patients with short- or mid-term life expectancy. 13,17,24

The results of our study seem to confirm the advantages of MISS. The study consisted of 42 patients with different primary tumors, who presented with a low KPS score and acute myelopathy due to spinal cord compression, compromising their QOL. Furthermore, all of the patients had low modified Bauer scores, which meant that they only required a short- or mid-term surgical palliation through posterior decompression and spinal segmental fixation. ${ }^{20}$ All patients underwent fixation, either because they presented with a clear preoperative instability or to prevent postsurgical instability ${ }^{34} \mathrm{~A}$ major surgical approach, which aimed for a gross-total or complete resection of metastases, was not indicated for any of the patients in the series.

The main goal of the MISS technique is to avoid large exposure and detachment of the paraspinal muscles through percutaneous insertion of pedicle screws and rods 
and the use of the mini-open midline approach, thus resulting in reduced bleeding and postoperative pain. Using the standard techniques of fixation, all of the posterior elements from the vertebra above to the vertebra below the involved segments are exposed and skeletonized, resulting in much more aggressive damage to the back muscles and soft tissues. We have always placed the shortest possible implant, compatible with the biological behavior of the lesion (i.e., osteolytic or osteoblastic), the number of segments involved, and the columns involved for each segment. To this aim, in cases in which the lesion was partially invading the vertebra, pedicle screws are also inserted in the fractured vertebrae.

We strongly suggest a 4 -handed surgery with the 2 radiography arches to insert the pedicle screws in order to reduce the operation time and minimize radiation exposure. Nevertheless, criticism remains in terms of the ability of MISS to obtain satisfactory spinal cord decompression, due to the erroneous conviction that the greater the surgical exposure, the better results achieved. This conviction must finally be eradicated. In fact, MISS techniques have demonstrated easy access to the spinal canal and complete spinal cord decompression and roots.

Our results demonstrate that the standard open surgery techniques and the MISS techniques are equivalent in terms of the ability to achieve early neurological improvement in patients with acute myelopathy due to spinal cord compression. Our results confirm that the MISS technique has a clear and significant advantage over standard open techniques in terms of blood loss, operation length, and hospital stay; the results also confirm the safety of the MISS technique, with no patients presenting with perioperative surgery-related complications.

We decided to compare the QOL results at an early follow-up, since, in patients with metastatic cancer, the late follow-up is generally conditioned by the progression of the primary disease, which can produce a bias when evaluating the surgical results for neurological restoration alone. Facing an equivalent neurological recovery, at the 30-day follow-up patients in the MISS group presented with a better outcome in terms of QOL than patients in the open surgery group. This result was confirmed by the functional and symptom scale scores. This result is particularly important for a series of patients with short- to mid-term life expectancy.

Some patients in our series presented with early worsening of neurological conditions and/or pain due to the severity of their preoperative status, which conditioned the postoperative results. All of these patients were older than 60 years, except one, who presented a history of drug addiction. This result suggests that age is a very important prognostic factor to consider in patients with metastatic disease before choosing surgical strategies, especially those with more aggressive disease.

The advantage of MISS techniques in achieving an early better QOL seems to be related to their ability to reduce postoperative pain for both surgery-related and spinal metastasis-related components. In fact, VAS score improvement was significantly greater and the need for opioids was significantly lower in patients in the MISS group than patients in the open surgery group. The reduction in the administration of opioids is a useful and important result, since their prolonged use can lead to complications in patients with systemic metastases, such as severe constipation or alterations in consciousness.

\section{Conclusions}

Surgery is a palliative but mandatory treatment for patients with myelopathy due to vertebral metastases, with the aim to preserve or, whenever possible, improve QOL. Although MISS and open surgery are equivalent in terms of safety and early neurological recovery, MISS seems to reduce the length of surgery, blood loss, hospital stay, and the need for postoperative opioid agents; these effects appear to translate to a better QOL. In our opinion, MISS techniques should be the first choice of treatment for spine metastatic patients with myelopathy, because they may obtain as safe and effective spinal cord decompression and spine fixation as that with traditional surgery, and also may reduce the impact of surgery in critical patients. Further studies are needed to confirm these findings.

\section{Acknowledgment}

We thank San Francisco Edit for linguistic improvements.

\section{References}

1. Aaronson NK, Ahmedzai S, Bergman B, Bullinger M, Cull A, Duez NJ, et al: The European Organization for Research and Treatment of Cancer QLQ-C30: a quality-of-life instrument for use in international clinical trials in oncology. $\mathbf{J}$ Natl Cancer Inst 85:365-376, 1993

2. Assaker R: Minimal access spinal technologies: state-of-theart, indications, and techniques. Joint Bone Spine 71:459469, 2004

3. Beisse R: Endoscopic surgery on the thoracolumbar junction of the spine. Eur Spine J 15:687-704, 2006

4. Bhatt AD, Schuler JC, Boakye M, Woo SY: Current and emerging concepts in non-invasive and minimally invasive management of spine metastasis. Cancer Treat Rev 39:142152,2013

5. Binning MJ, Gottfried ON, Klimo P Jr, Schmidt MH: Minimally invasive treatments for metastatic tumors of the spine. Neurosurg Clin N Am 15:459-465, 2004

6. Chi JH, Gokaslan ZL: Vertebroplasty and kyphoplasty for spinal metastases. Curr Opin Support Palliat Care 2:9-13, 2008

7. Chow E, Hird A, Velikova G, Johnson C, Dewolf L, Bezjak A, et al: The European Organisation for Research and Treatment of Cancer Quality of Life Questionnaire for patients with bone metastases: the EORTC QLQ-BM22. Eur J Cancer 45:1146-1152, 2009

8. Chow E, Nguyen J, Zhang L, Tseng LM, Hou MF, Fairchild $A$, et al: International field testing of the reliability and validity of the EORTC QLQ-BM22 module to assess health-related quality of life in patients with bone metastases. Cancer 118:1457-1465, 2012

9. Fayers PM, Aaronson NK, Bjordal K, Grønvold M, Curran D, Bottomley A: The EORTC QLQ-C30 Scoring Manual. Brussels: European Organisation for Research and Treatment of Cancer, 2001

10. Harel R, Angelov L: Spine metastases: current treatments and future directions. Eur J Cancer 46:2696-2707, 2010

11. Heidecke V, Rainov NG, Burkert W: Results and outcome of neurosurgical treatment for extradural metastases in the cervical spine. Acta Neurochir (Wien) 145:873-881, 2003 
12. Holly LT, Schwender JD, Rouben DP, Foley KT: Minimally invasive transforaminal lumbar interbody fusion: indications, technique, and complications. Neurosurg Focus 20(3):E6, 2006

13. Hsieh PC, Koski TR, Sciubba DM, Moller DJ, O'Shaughnessy BA, Li KW, et al: Maximizing the potential of minimally invasive spine surgery in complex spinal disorders. Neurosurg Focus 25(2):E19, 2008

14. Huang TJ, Hsu RW, Li YY, Cheng CC: Minimal access spinal surgery (MASS) in treating thoracic spine metastasis. Spine (Phila Pa 1976) 31:1860-1863, 2006

15. Ibrahim A, Crockard A, Antonietti P, Boriani S, Bünger C, Gasbarrini A, et al: Does spinal surgery improve the quality of life for those with extradural (spinal) osseous metastases? An international multicenter prospective observational study of 223 patients. J Neurosurg Spine 8:271-278, 2008

16. Jakobs TF, Trumm C, Reiser M, Hoffmann RT: Percutaneous vertebroplasty in tumoral osteolysis. Eur Radiol 17:21662175,2007

17. Kan P, Schmidt MH: Minimally invasive thoracoscopic approach for anterior decompression and stabilization of metastatic spine disease. Neurosurg Focus 25(2):E8, 2008

18. Kanter AS, Mummaneni PV: Minimally invasive spine surgery. Neurosurg Focus 25(2):E1, 2008

19. Khan SN, Donthineni R: Surgical management of metastatic spine tumors. Orthop Clin North Am 37:99-104, 2006

20. Leithner A, Radl R, Gruber G, Hochegger M, Leithner K, Welkerling $\mathrm{H}$, et al: Predictive value of seven preoperative prognostic scoring systems for spinal metastases. Eur Spine J 17:1488-1495, 2008

21. Logroscino CA, Proietti L, Tamburrelli FC: Minimally invasive spine stabilisation with long implants. Eur Spine J 18 (Suppl 1):75-81, 2009

22. McLain RF, Lieberman IH: Endoscopic approaches to metastatic thoracic disease. Spine (Phila Pa 1976) 25:1855-1858, 2000

23. Miscusi M, Domenicucci M, Polli FM, Forcato S, De Giorgio F, Raco A: Spondylectomy of T-2 according to the Tomita technique via an extended Fessler approach: a cadaveric study. J Neurosurg Spine 16:22-26, 2012

24. Mobbs RJ, Sivabalan P, Li J: Technique, challenges and indications for percutaneous pedicle screw fixation. J Clin Neurosci 18:741-749, 2011

25. Ofluoglu O: Minimally invasive management of spinal metastases. Orthop Clin North Am 40:155-168, viii, 2009

26. Oppenheimer JH, DeCastro I, McDonnell DE: Minimally invasive spine technology and minimally invasive spine surgery: a historical review. Neurosurg Focus 27(3):E9, 2009

27. Ortiz Gómez JA: The incidence of vertebral body metastases. Int Orthop 19:309-311, 1995

28. Patchell RA, Tibbs PA, Regine WF, Payne R, Saris S, Kryscio RJ, et al: Direct decompressive surgical resection in the treatment of spinal cord compression caused by metastatic cancer: a randomised trial. Lancet 366:643-648, 2005

29. Pizzoli AL, Brivio LR, Caudana R, Vittorini E: Percutaneous CT-guided vertebroplasty in the management of osteoporotic fractures and dorsolumbar metastases. Orthop Clin North Am 40:449-458, vii, 2009

30. Quraishi NA, Gokaslan ZL, Boriani S: The surgical management of metastatic epidural compression of the spinal cord. $\mathbf{J}$ Bone Joint Surg Br 92:1054-1060, 2010

31. Rose PS, Buchowski JM: Metastatic disease in the thoracic and lumbar spine: evaluation and management. J Am Acad Orthop Surg 19:37-48, 2011

32. Rosenthal D, Marquardt G, Lorenz R, Nichtweiss M: Anterior decompression and stabilization using a microsurgical endoscopic technique for metastatic tumors of the thoracic spine. J Neurosurg 84:565-572, 1996

33. Selznick LA, Shamji MF, Isaacs RE: Minimally invasive interbody fusion for revision lumbar surgery: technical feasibility and safety. J Spinal Disord Tech 22:207-213, 2009

34. Tomita K, Kawahara N, Baba H, Tsuchiya H, Fujita T, Toribatake Y: Total en bloc spondylectomy. A new surgical technique for primary malignant vertebral tumors. Spine (Phila Pa 1976) 22:324-333, 1997

35. Weber MH, Burch S, Buckley J, Schmidt MH, Fehlings MG, Vrionis FD, et al: Instability and impending instability of the thoracolumbar spine in patients with spinal metastases: a systematic review. Int J Oncol 38:5-12, 2011

36. Winstead ER: After treatment: the needs of cancer survivors. NCI Cancer Bull 2:1-2, 2005

37. Witham TF, Khavkin YA, Gallia GL, Wolinsky JP, Gokaslan ZL: Surgery insight: current management of epidural spinal cord compression from metastatic spine disease. Nat Clin Pract Neurol 2:87-94, 2006

38. Wong DA, Fornasier VL, MacNab I: Spinal metastases: the obvious, the occult, and the impostors. Spine (Phila Pa 1976) 15:1-4, 1990

39. Zairi F, Marinho P, Allaoui M, Assaker R: [New advances in the management of thoracolumbar spine metastasis.] Bull Cancer 100:435-441, 2013 (Fr)

\section{Author Contributions}

Conception and design: Miscusi, Raco Acquisition of data: Miscusi, Polli, Forcato, Ricciardi, Frati, Cimatti, De Martino. Analysis and interpretation of data: Miscusi, Polli, Forcato, Frati, Raco. Drafting the article: Miscusi. Critically revising the article: Ramieri, Raco. Reviewed submitted version of manuscript: Miscusi, Raco. Approved the final version of the manuscript on behalf of all authors: Miscusi. Statistical analysis: Miscusi, Forcato, Ricciardi, Ramieri. Administrative/technical/material support: Miscusi, Polli, Forcato, Ricciardi, Frati, Cimatti, De Martino, Ramieri. Study supervision: Miscusi, Raco.

\section{Correspondence}

Massimo Miscusi, Department of Neurological Science, Section of Neurosurgery, Sapienza University of Rome, 04100 Latina, Italy.email: m.miscusi@libero.it. 